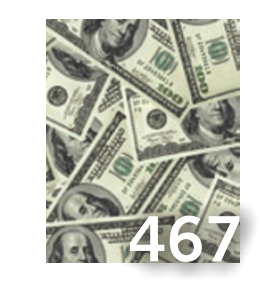

\section{Stimulus pie:}

The NIH must divvy

up $\$ 10.4$ billion in

added funding

A master's degree with a business spin gains popularity

Strategic science:

Harvey Fineberg of the IOM weighs plans for medicine
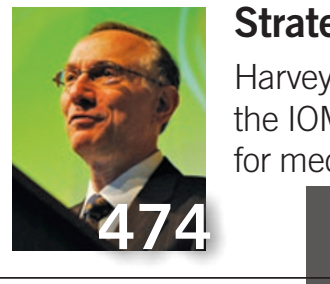

Working as a quality control tester in a juice factory, Brendan Tierney knew he wanted to go back to school and pursue science. But Tierney faced two problems: he did not know which specific area of biomedical science to focus on, nor did he have a sense of how he could eventually use graduate training to land a better job.

He considered pursuing a $\mathrm{PhD}$, but was put off by the narrow focus and long lead time of this type of degree. He also looked at traditional master's degree programs but ultimately passed them over when he found out about a new type of qualification: the professional science master's (PSM) degree. PSM curriculum includes individually tailored coursework in the sciences and hands-on training through internships.

Tierney now has a PSM degree in applied genomics and a good job in a natural products lab, where he researches antiviral and anticancer compounds. "I would never have heard about this job without the program, and the internships gave me the necessary experience to land it," he says.

PSM programs are on the rise. In the 2009 stimulus bill, the US Congress allocated \$15 million specifically for the development of PSM programs. Even before the federal boost, the number of such programs nationwide has risen from just one in 1997 (when the Alfred P. Sloan Foundation funded the first program) to 138 programs at 67 institutions in 2008. In the last year alone, 19 institutions launched a total of 28 new PSM programs, according to the National Professional Science Masters Association (NPSMA).

Not surprisingly, increasing numbers of programs drive up the number of graduates. Although about 2,700 people have graduated with PSM degrees to date, roughly the same number of students are currently pursuing PSM degrees in the US - over half in fields related to biomedicine. These numbers could increase by $25 \%$ over the next two to three years, according to Stephen Lemire, director of NPSMA. "PSM degrees have been the silent success in modern science education," says Eleanor Babco, who co-directs the PSM Initiative at the Washington, DC-based Council of Graduate Schools.

Despite the programs' rise, the coursework involved remains variable. Typically, PSM curricula combine science and management training into a two-year program tailored to meet the demands of industry jobs. Companies directly support these programs through funding and by helping to build employer advisory boards. Most PSM programs involve a flexible mix of science courses plus several business courses in areas such as marketing, communications and project management, as well as up to three internships of the student's choosing. PSM students typically share some science faculty with their counterparts enrolled in traditional master's programs.

PSM programs are relatively new, and national standards allow for latitude and variation. "I wouldn't be surprised at weaknesses in individual programs. Some programs develop nonscience ties better than others," explains Daryl Chubin, director of the Center for Advancing Science \& Engineering Capacity at the American Association for the Advancement of Science. He explains that building the business component of the curriculum requires enormous work. Without good cooperation between universities and industry, students sometimes lack choices in the business classes offered toward a PSM.

\section{New transitions}

In rare cases, students make the jump to a $\mathrm{PhD}$ program after only a few months of PSM coursework. "PSMs are targeted for people who want to go into industry, and I knew after six months that I wanted to spend more time in the lab," says Dawn Carone, who made the switch to a PhD track.

But transitions also happen in the reverse direction; for example, Kali Bogaard felt unsure about her chosen field of forensics and wasn't ready to commit to a $\mathrm{PhD}$ program or a regular master's degree, so she opted for a PSM degree. "The PSM offered variation, well rounded training and allowed me to change direction [to genetics] without starting all over," Bogaard explains.

The main appeal of the degree to students seems to be a fast, portable and specific degree that can lead to a job in industry or research that pays more-at least $\$ 10,000$ more per year than a traditional master's degree, according to the NPSMA.

Women in particular are attracted to the degree. Most recent figures show that $46 \%$ of enrollees in PSM programs are women, which experts say is a higher percentage than that found in traditional science master's programs. For example, Sandra Canosa wanted to advance her existing bench research career and earnings potential to better support her family. "My main reason for choosing a PSM, and for not choosing a $\mathrm{PhD}$ or regular master's, was financial," says Canosa.

The popularity of PSMs challenges the long held notion that a master's degree in science is a consolation prize in a failed $\mathrm{PhD}$ attempt, according to Linda Strausbaugh, director of the PSM program at the University of Connecticut in Storrs.

An early skeptic, Strausbaugh changed her mind after a few years when she realized that there is a deep pool of talented people who do not want to get a PhD but still want to work in science. She explains that earning a PSM is a way for students to access many of the career destinations available only to candidates with specific science training.

Genevive Bjorn, Maui, Hawaii

PSM Degree Programs by Discipline (2008)

\begin{tabular}{ll}
\hline Field of Study & $\begin{array}{c}\text { \# of } \\
\text { Programs }\end{array}$ \\
$\begin{array}{l}\text { Bioinformatics/Biotechnology } \\
\text { Environmental and Geosciences }\end{array}$ & 40 \\
$\begin{array}{l}\text { Financial Mathematics/ Industrial } \\
\text { Mathematics }\end{array}$ & 13 \\
$\begin{array}{l}\text { Analytical Chemistry/ Biochemistry/ } \\
\text { Forensics }\end{array}$ & 12 \\
$\begin{array}{l}\text { Health Physics/Medical Physics } \\
\text { Microbiology/ Cell and Molecular }\end{array}$ & 12 \\
$\begin{array}{l}\text { Biology } \\
\text { Applied Statistics/ Computational }\end{array}$ & 10 \\
Science & 9 \\
Applied/Industrial Physics & 8 \\
Food Safety/Pharmacology and & 3 \\
Toxicology & \\
Total Number of PSM Degree Programs & 124 \\
Source: National Professional Science Master's Association
\end{tabular}

